\title{
Short Communication Sleep duration and the risk of breast cancer: the Ohsaki Cohort Study
}

\author{
M Kakizaki, ', , S Kuriyama', T Sone', K Ohmori-Matsuda', A Hozawa', N Nakaya', S Fukudo ${ }^{2}$ and I Tsuji' \\ 'Division of Epidemiology, Department of Public Health and Forensic Medicine, Tohoku University Graduate School of Medicine, Sendai, Japan; ${ }^{2}$ Division \\ of Behavioral Medicine, Department of Functional Medical Science, Tohoku University Graduate School of Medicine, Sendai, Japan
}

In a prospective study of 23995 Japanese women, short sleep duration was associated with higher risk of breast cancer (I 43 cases), compared with women who slept $7 \mathrm{~h}$ per day, the multivariate hazard ratio of those who slept $\leqslant 6 \mathrm{~h}$ per day was 1.62 ( $95 \%$ confidence interval: I.05-2.50; $P$ for trend $=0.03$ ).

British Journal of Cancer (2008) 99, I502-1505. doi:I0.1038/sj.bjc.6604684 www.bjcancer.com

Published online 23 September 2008

(c) 2008 Cancer Research UK

Keywords: sleep duration; breast cancer; incidence; Japanese; prospective cohort study

Breast cancer is the commonest cancer in women, worldwide (Parkin et al, 2005). In Japan, the incidence rate age-standardised to the world population was 28.3 per 100000 in 1991 and 39.5 in 2001 (The Research Group for Population-based Cancer Registration in Japan, 1998; Marugame et al, 2007).

Melatonin, which is secreted mainly from the pineal gland and plays a role in sleep duration, is suggested as an agent in the association between sleep duration and breast cancer (Brzezinski, 1997; Schernhammer and Schulmeister, 2004). This is because melatonin suppresses the synthesis and secretion of sex hormones by promoting the release of gonadotropin-releasing hormone (Martin and Klein, 1976; Aleandri et al, 1996). In relation to melatonin secretion, there have been several observational studies on night work or visual impairment and breast cancer (Feychting et al, 1998; Verkasalo et al, 1999; Kliukiene et al, 2001; Schernhammer et al, 2001; Megdal et al, 2005; Pukkala et al, 2006; Schwartzbaum et al, 2007). In addition, there have been three prospective cohort studies of sleep duration and the risk of breast cancer, although with inconsistent findings (Verkasalo et al, 2005; Pinheiro et al, 2006; Wu et al, 2008).

We therefore examined the association between sleep duration and the risk of breast cancer in a population of Japanese women.

\section{MATERIALS AND METHODS}

Details of the Ohsaki National Health Insurance (NHI) Cohort Study have been described previously (Tsuji et al, 1998; Kuriyama et al, 2006). Briefly, this prospective cohort study, started in 1994, included 28515 women aged 40-79 years living in the 14 municipalities of Miyagi Prefecture, northeastern Japan. The

*Correspondence: M Kakizaki, Division of Epidemiology, Department of Public Health and Forensic Medicine, Tohoku University Graduate School of Medicine, 2-I Seiryo-machi, Aoba-ku, Sendai, Miyagi 980-8575, Japan; E-mail: m-kaki@umin.ac.jp

Received 7 July 2008; revised 29 August 2008; accepted I September 2008; published online 23 September 2008 response rate was $95.0 \%(N=27134)$ for the questionnaire, including items on sleep duration and other health-related lifestyle factors. The study protocol was reviewed and approved by the ethics committee of Tohoku University School of Medicine.

After exclusion of participants who had withdrawn from the NHI before follow-up, those who had history of cancer, those who had omitted responses for sleep duration, and those who had reported sleep duration of less than $4 \mathrm{~h}$ or more than $12 \mathrm{~h}, 23995$ participants remained. To follow up participants for mortality and migration, we reviewed the NHI withdrawal history files for 1995-2003. Through the Miyagi Prefectural Cancer Registry, we identified 143 incident cases of breast cancer.

With regard to the sleep duration, participants answered the mean integer number of hours of sleep per day during the last year. Because of the small number who slept for less than $7 \mathrm{~h}$ and less than $8 \mathrm{~h}$, we categorised sleep duration into four groups: $\leqslant 6$, 7,8 , and $\geqslant 9 \mathrm{~h}$ per day. We estimated hazard ratios (HRs) and $95 \%$ confidence intervals (CIs) of breast cancer incidence according to sleep duration, using the Cox proportional hazards model, with adjustment for age and potential confounders. The continuous $P$ for trend was calculated by treating sleep duration as a continuous variable, and the categorical $P$ for trend by treating each category as a continuous variable. Interactions between the risk and all confounders were tested through the addition of crossproduct terms to multivariate model.

All statistical analyses were performed using SAS statistical software, version 9.1 (SAS Institute Inc, Cary, NC, USA), and all those reported were two-sided; differences at $P$-values of $<0.05$ were accepted as significant.

\section{RESULTS}

Table 1 shows the baseline characteristics of participants according to sleep duration. Participants who slept $6 \mathrm{~h}$ or less were more likely to have a family history of cancer, to have used oral contraceptive drugs, and to be premenopausal. Participants who slept $9 \mathrm{~h}$ or more were older, had a smaller total caloric intake, lower educational level, were more likely to have a history of 
Table I Baseline characteristics of the participants according to sleep duration

\begin{tabular}{|c|c|c|c|c|}
\hline & \multicolumn{4}{|c|}{ Sleep duration (hours per day) } \\
\hline & $\leqslant 6$ & 7 & 8 & $\geqslant 9$ \\
\hline Mean age (years), s.d. ${ }^{a}$ & $58.8(10.5)$ & $58.3(10.0)$ & $61.4(9.3)$ & $66.4(8.7)$ \\
\hline Mean body mass index $\left(\mathrm{kg} \mathrm{m}^{-2}\right)$, s.d. ${ }^{\mathrm{a}}$ & $23.6(3.3)$ & $23.7(3.3)$ & $23.8(3.4)$ & $24.0(3.9)$ \\
\hline Mean total caloric intake $\left(\mathrm{kcal}^{\mathrm{day}}{ }^{-1}\right)$, s.d. ${ }^{\mathrm{a}}$ & $1220.2(378.8)$ & $1263.0(367.7)$ & $1242.1(380.0)$ & $1171.8(410.6)$ \\
\hline \multicolumn{5}{|l|}{ History of diseases (\%) ${ }^{\mathrm{b}}$} \\
\hline Absence & 70.1 & 71.3 & 65.8 & 55.8 \\
\hline \multicolumn{5}{|l|}{ Family history of cancer in first-degree relatives (\%) } \\
\hline Presence & 35.0 & 33.1 & 31.1 & 29.7 \\
\hline Absence & 65.0 & 66.9 & 68.9 & 70.3 \\
\hline \multicolumn{5}{|l|}{ Job (\%) } \\
\hline Unmarried & 23.8 & 18.9 & 20.0 & 27.3 \\
\hline \multicolumn{5}{|l|}{ Education (\%) } \\
\hline Junior high school or less & 46.9 & 46.8 & 57.6 & 66.3 \\
\hline High school & 36.8 & 39.0 & 29.6 & 18.2 \\
\hline College/university or higher & 10.4 & 9.0 & 6.2 & 3.4 \\
\hline \multicolumn{5}{|l|}{ Cigarette smoking (\%) } \\
\hline Never smoker & 69.1 & 72.2 & 68.9 & 65.3 \\
\hline Ex-smoker & 2.7 & 1.8 & 1.8 & 2.2 \\
\hline Current smoker ( $<20$ cigarettes per day) & 5.7 & 4.2 & 3.3 & 2.8 \\
\hline Current smoker ( $\geqslant 20$ cigarettes per day) & 3.2 & 2.1 & 1.4 & 1.1 \\
\hline \multicolumn{5}{|l|}{ Alcohol consumption (\%) } \\
\hline \multicolumn{5}{|l|}{ Walking status (\%) } \\
\hline \multicolumn{5}{|l|}{ Menopausal status (\%) } \\
\hline Premenopausal & 23.7 & 23.5 & 13.9 & 5.7 \\
\hline Postmenopausal & 62.5 & 62.5 & 68.2 & 68.1 \\
\hline \multicolumn{5}{|l|}{ Age at menarche (\%) } \\
\hline$\leqslant 13$ years & 7.0 & 7.4 & 6.3 & 5.4 \\
\hline $14-5$ years & 19.5 & 20.5 & 20.7 & 17.0 \\
\hline$\geqslant 16$ years & 18.1 & 16.7 & 19.6 & 22.2 \\
\hline \multicolumn{5}{|l|}{ Age at first delivery (\%) } \\
\hline$\leqslant 21$ years & 16.3 & 16.0 & 18.3 & 20.6 \\
\hline $22-5$ years & 48.4 & 52.1 & 50.6 & 45.2 \\
\hline$\geqslant 26$ years & 20.6 & 18.8 & 16.1 & 13.1 \\
\hline \multicolumn{5}{|l|}{ Number of deliveries (\%) } \\
\hline 0 births & 3.1 & 2.7 & 2.8 & 3.0 \\
\hline I- births & 39.3 & 40.0 & 35.3 & 22.4 \\
\hline$\geqslant 3$ births & 43.6 & 45.4 & 47.2 & 52.7 \\
\hline \multicolumn{5}{|l|}{ Using of oral contraceptive drugs (\%) } \\
\hline Yes & 5.1 & 4.4 & 3.1 & 2.5 \\
\hline No & 81.0 & 82.5 & 79.2 & 72.9 \\
\hline \multicolumn{5}{|c|}{ Using of hormone drugs except for oral contraceptive drugs (\%) } \\
\hline Yes & 8.1 & 6.8 & 6.3 & 5.7 \\
\hline No & 77.9 & 79.7 & 76.4 & 69.3 \\
\hline
\end{tabular}

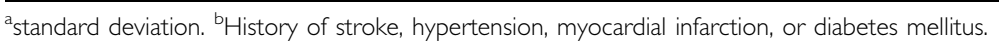


Table 2 Cox proportional hazard ratios (HRs) and 95\% confidence intervals (Cls) for breast cancer incidence according to sleep duration in Japanese women

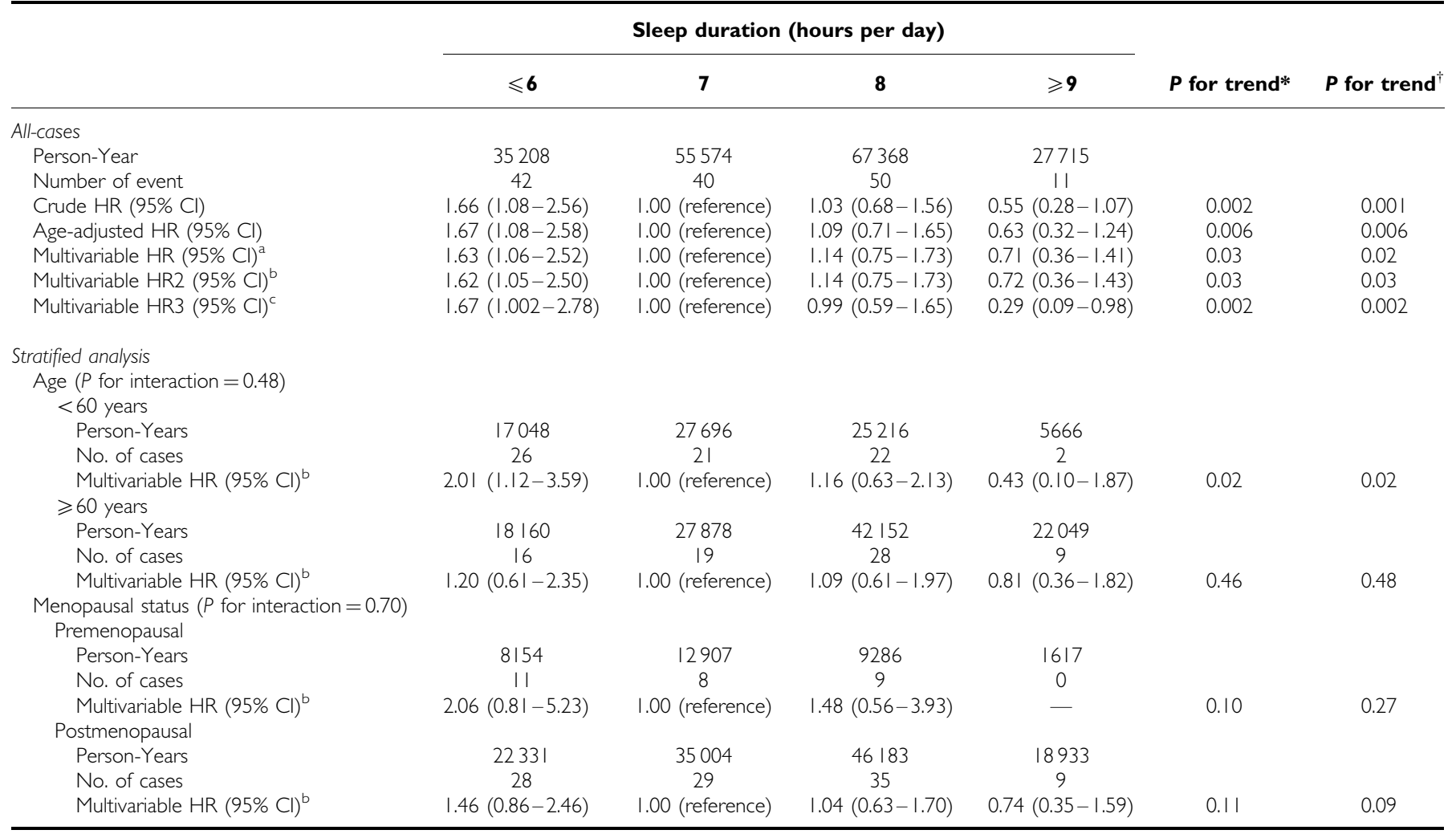

*P for trend values were calculated by treating sleep duration as a continuous variable. ${ }^{\dagger} P$ for trend values were calculated by treating each categories of sleep duration as a continuous variable. ${ }^{a}$ Multivariable HR was adjusted for age (continuous variable); body mass index $\left(<18.5,18.5-25.0, \geqslant 25.0 \mathrm{~kg} \mathrm{~m}^{-2}\right.$ ); history of diseases (having history of stroke, hypertension, myocardial infarction, or diabetes mellitus); family history of cancer (presence or absence in first-degree relatives); job (employed or unemployed); marital status (married or unmarried); education (junior high school or less, high school, or college/university or higher); cigarette smoking (never smoker, ex-smoker, current smoker I 19 cigarettes per day, or current smoker $\geqslant 20$ cigarettes per day); alcohol consumption (never drinker, ex-drinker, or current drinker); time spent walking (less than I h per day, or longer than I h per day). 'Multivariable HR2 was adjusted for above plus total caloric intake (continuous variable, kcal day ${ }^{-1}$ ); menopausal status (premenopausal or postmenopausal); age at menarche ( $\leqslant 13$ years, $14-15$ years, or $\geqslant 16$ years); age at first delivery ( $\leqslant 21$ years, $22-25$ years, or $\geqslant 26$ years); number of deliveries $(0$ births, $1-2$ births, or $\geqslant 3$ births); using of oral contraceptive drugs (yes or no); using of hormone drugs except for oral contraceptive drugs (yes or no). ${ }^{\circ}$ Multivariable HR3 denotes the HR2 with cases diagnosed in the first 3 years of follow-up excluded from the analysis.

diseases, and were less likely to be employed, married, and premenopausal.

Using women who slept $7 \mathrm{~h}$ as the reference group, we found an inverse association between sleep duration and breast cancer risk. The HR of women who slept $6 \mathrm{~h}$ or less was 1.62 (95\% CI: $1.05-2.50)$, of those who slept $8 \mathrm{~h}$ was 1.14 (95\% CI: $0.75-1.73$ ), and of those who slept $9 \mathrm{~h}$ or more was 0.72 (95\% CI: $0.36-1.43$ ) $(P$ for trend $=0.03$ ). This result did not change substantially when participants whose event occurred within 3 years of baseline $(N=49)$ were excluded and stratified analysis by age and menopausal status (Table 2). In addition, we examined in detail confounding and effect modification by other covariates on the associations between sleep duration and the risk of breast cancer. No statistically significant interaction was observed between sleep duration and other confounding factors for the risk of breast cancer on a multiplicative scale (data not shown).

\section{DISCUSSION}

This study revealed an inverse association between sleep duration and the risk of breast cancer in Japanese women, participants who slept $6 \mathrm{~h}$ or daily having a significantly increased risk of breast cancer.
There have been three prospective cohort studies of breast cancer in relation to sleep duration (Verkasalo et al, 2005; Pinheiro et al, 2006; Wu et al, 2008), of which the last two reported a significantly decreased risk in long sleepers and our results are consistent with these. By contrast, another study reported no such association (Pinheiro et al, 2006), possibly studied because residential nurses were studied with rotating-shift work and varying timing of sleep, so that generalising from their results may be inappropriate.

Melatonin is suggested to be involved in this relationship with sleep duration, a decrease that results in a shorter duration of nocturnal melatonin secretion (Wehr, 1991). A lower melatonin level was associated with an increased risk of breast cancer (Schernhammer and Hankinson, 2005; Schernhammer et al, 2008). Melatonin may have an inhibitory effect on gonadal function, including the synthesis and secretion of sex hormones, by promoting the release of gonadaotropin-releasing hormone (Martin and Klein, 1976; Aleandri et al, 1996); it also exerts an antiproliferative effect on breast cancer cell lines (Blask et al, 1997).

Our study had several strengths. First, we recruited participants from the general population, allowing possible generalisation of our results. Second, the Miyagi Prefectural Cancer Registry is one of the earliest and most accurate population-based cancer 
registries in Japan (Takano and Okuno, 1997), with only $2.7 \%$ of breast cancer cases ascertained by death certificate only (DCO) in 1998-2002 (Curado et al, 2007).

Our study also had several methodological limitations. First, we used self-reported sleep duration, and the assessment was done only once. Second, we had no information on such factors as sleep quality, the timing of sleep, the use of sleep medication, or the presence of sleeping disorders that can influence sleep duration and thereby might affect breast cancer risk. Finally, we had no information about rotating-shift work or night work, but since $23 \%$ of our participants were housewives, $19.0 \%$ farmers, and $15.7 \%$ retired, such details would have been unlikely to have changed the result substantially.

\section{REFERENCES}

Aleandri V, Spina V, Morini A (1996) The pineal gland and reproduction. Hum Reprod Update 2: 225-235

Blask DE, Wilson ST, Zalatan F (1997) Physiological melatonin inhibition of human breast cancer cell growth in vitro: evidence for a glutathionemediated pathway. Cancer Res 57: 1909-1914

Brzezinski A (1997) Melatonin in humans. N Engl J Med 336: 186-195

Curado M, Edwards B, Shin H, Storm H, Ferlay J, Heanue M, Boyle P (2007)

Cancer Incidence in Five Continents, Vol IX In IARC Scientific Publications IARC: Lyon

Feychting M, Osterlund B, Ahlbom A (1998) Reduced cancer incidence among the blind. Epidemiology 9: 490-494

Kliukiene J, Tynes T, Andersen A (2001) Risk of breast cancer among Norwegian women with visual impairment. Br J Cancer 84: 397 - 399

Kuriyama S, Shimazu T, Ohmori K, Kikuchi N, Nakaya N, Nishino Y, Tsubono Y, Tsuji I (2006) Green tea consumption and mortality due to cardiovascular disease, cancer, and all causes in Japan: the Ohsaki study. JAMA 296: $1255-1265$

Martin JE, Klein DC (1976) Melatonin inhibition of the neonatal pituitary response to luteinizing hormone-releasing factor. Science 191: $301-302$

Marugame T, Matsuda T, Kamo K, Katanoda K, Ajiki W, Sobue T (2007) Cancer incidence and incidence rates in Japan in 2001 based on the data from 10 population-based cancer registries. Jpn J Clin Oncol 37: 884-891

Megdal SP, Kroenke CH, Laden F, Pukkala E, Schernhammer ES (2005) Night work and breast cancer risk: a systematic review and metaanalysis. Eur J Cancer 41: 2023-2032

Parkin DM, Bray F, Ferlay J, Pisani P (2005) Global cancer statistics, 2002. CA Cancer J Clin 55: 74-108

Pinheiro SP, Schernhammer ES, Tworoger SS, Michels KB (2006) A prospective study on habitual duration of sleep and incidence of breast cancer in a large cohort of women. Cancer Res 66: $5521-5525$

Pukkala E, Ojamo M, Rudanko SL, Stevens RG, Verkasalo PK (2006) Does incidence of breast cancer and prostate cancer decrease with increasing degree of visual impairment. Cancer Causes Control 17: 573-576

Schernhammer ES, Berrino F, Krogh V, Secreto G, Micheli A, Venturelli E, Sieri S, Sempos CT, Cavalleri A, Schunemann HJ, Strano S, Muti P (2008) Urinary 6-sulfatoxymelatonin levels and risk of breast cancer in postmenopausal women. J Natl Cancer Inst 100: 898-905
In conclusion, we have found a significant inverse association between sleep duration and breast cancer risk in Japanese women, those who slept $6 \mathrm{~h}$ or less having a significantly increased risk.

\section{ACKNOWLEDGEMENTS}

This study was supported by a Grant-in-Aid for Cancer Research and for the Third Term Comprehensive Ten-Year Strategy for Cancer Control (H18-3jigan-ippan-001), Ministry of Health, Labour and Welfare, Japan. Masako Kakizaki was supported in part by Global COE Program (Basic and Translational Research Center for Global Brain Science), MEXT, Japan.

Schernhammer ES, Hankinson SE (2005) Urinary melatonin levels and breast cancer risk. J Natl Cancer Inst 97: 1084-1087

Schernhammer ES, Laden F, Speizer FE, Willett WC, Hunter DJ, Kawachi I, Colditz GA (2001) Rotating night shifts and risk of breast cancer in women participating in the nurses' health study. J Natl Cancer Inst 93: $1563-1568$

Schernhammer ES, Schulmeister K (2004) Melatonin and cancer risk: does light at night compromise physiologic cancer protection by lowering serum melatonin levels? $\mathrm{Br} J$ Cancer 90: 941 - 943

Schwartzbaum J, Ahlbom A, Feychting M (2007) Cohort study of cancer risk among male and female shift workers. Scand J Work Environ Health 33: $336-343$

Takano A, Okuno Y (1997) Japan, Miyagi Prefecture. In: International Agency for Research on Cancer, Parkin D, Whelan S, Ferlay J, Raymond L, Young J (eds) Vol. 17, pp 386-389. IARC: Lyon

The Research Group for Population-based Cancer Registration in Japan (1998) Cancer incidence in Japan in 1991: estimates based on data from population-based cancer registries. The Research Group for Populationbased Cancer Registration in Japan (5-3). Jpn J Clin Oncol 28: $574-577$

Tsuji I, Nishino Y, Ohkubo T, Kuwahara A, Ogawa K, Watanabe Y, Tsubono Y, Bando T, Kanemura S, Izumi Y, Sasaki A, Fukao A, Nishikori M, Hisamichi S (1998) A prospective cohort study on National Health Insurance beneficiaries in Ohsaki, Miyagi Prefecture, Japan: study design, profiles of the subjects and medical cost during the first year. $J$ Epidemiol 8: $258-263$

Verkasalo PK, Lillberg K, Stevens RG, Hublin C, Partinen M, Koskenvuo M, Kaprio J (2005) Sleep duration and breast cancer: a prospective cohort study. Cancer Res 65: 9595-9600

Verkasalo PK, Pukkala E, Stevens RG, Ojamo M, Rudanko SL (1999) Inverse association between breast cancer incidence and degree of visual impairment in Finland. Br J Cancer 80: 1459-1460

Wehr TA (1991) The durations of human melatonin secretion and sleep respond to changes in daylength (photoperiod). J Clin Endocrinol Metab 73: $1276-1280$

Wu AH, Wang R, Koh WP, Stanczyk FC, Lee HP, Yu MC (2008) Sleep duration, melatonin and breast cancer among Chinese women in Singapore. Carcinogenesis 29(6): 1244-1248 